for J. Appl. Crystallography

\title{
Preferred orientation of ettringite in concrete fractures
}

Hans-Rudolf Wenk $^{1)}$, Paulo J.M. Monteiro ${ }^{2)}$, Martin Kunz ${ }^{3)}$, Kai Chen $^{3)}$, Nobumichi Tamura ${ }^{3)}$, Luca Lutterotti ${ }^{4)}$ and John Delacroz ${ }^{1)}$

${ }^{1)}$ Department of Earth and Planetary Science, University of California, Berkeley CA 94720, USA

${ }^{2)}$ Department of Civil and Environmental Engineering, University of California, Berkeley CA 94720, USA

3) Advanced Light Source, Lawrence Berkeley Laboratory, 1 Cyclotron Road, Berkeley CA 94720, USA.

${ }^{4)}$ Department of Materials Engineering, University of Trento, 38050 Trento, Italy.

\begin{abstract}
Sulfate attack and the accompanying crystallization of fibrous ettringite $\left(\mathrm{Ca}_{6} \mathrm{Al}_{2}(\mathrm{OH})_{12}\left(\mathrm{SO}_{4}\right)_{3}\right.$ $26 \mathrm{H}_{2} \mathrm{O}$ ) causes cracking and loss of strength in concrete structures. We are using hard synchrotron X-ray microdiffraction to quantify the orientation distribution of ettringite crystals. Diffraction images are analyzed with the Rietveld method to obtain information on textures. The analysis reveals that c-axes of the trigonal minerals are preferentially oriented perpendicular to the fracture surfaces. By averaging single crystal elastic properties over the orientation distribution we can estimate the elastic anisotropy of ettringite aggregates.
\end{abstract}

\section{Introduction}

Preferred orientation has considerable influence on the properties of a wide range of materials. Microtextures have been traditionally measured with backscatter electron diffraction (e.g. Dingley, 2004) but this technique fails if crystallites are strained and contain large numbers of defects. In this case a focused X-ray beam can be employed as it is available at synchrotron sources. Early applications of synchrotron X-rays for texture analysis has been to thin films (Player et al. 1992), plated alloys (Backstrom et al. 1996) and bone (Heidelbach et al. 1999). Since then the technique has greatly improved, especially by analyzing $2 \mathrm{D}$ images with the Rietveld method (Lonardelli et al. 2005). Here we apply the technique to a different material: microscopic veins in deteriorating concrete that are filled with the mineral ettringite.

Concrete may be subject to sulfate attack that can cause expansion in the matrix of concrete and lead to loss of strength and stiffness because of lack of cohesiveness in the cement hydration products. The source of sulfate ions can be external or internal. For the external sulfate attack, the sulfate in groundwaters can penetrate the porous matrix of concrete and react with hydration products leading to expansion and cracking of the matrix. There is a consensus that the expansion in concrete is caused by the crystallization of ettringite $\mathrm{Ca}_{6} \mathrm{Al}_{2}(\mathrm{OH})_{12}\left(\mathrm{SO}_{4}\right)_{3} 26 \mathrm{H}_{2} \mathrm{O}$ formed from the monosulfate hydrate $\mathrm{Ca}_{4} \mathrm{Al}_{2}(\mathrm{OH})_{12}\left(\mathrm{SO}_{4}\right) 6 \mathrm{H}_{2} \mathrm{O}$ which is present in the cement paste (e.g. Mehta and Monteiro, 2006). Other phases, such as $\mathrm{Ca}_{4} \mathrm{Al}_{2} \mathrm{O}_{26} \mathrm{H}_{38}, \mathrm{Ca}_{3} \mathrm{Al}_{2} \mathrm{O}_{6}$, and $\mathrm{Ca}_{4} \mathrm{Al}_{2} \mathrm{Fe}_{2} \mathrm{O}_{10}$ can also be sources of the aluminate ions in the formation of ettringite. The reaction to generate ettringite from monosulfate, starts with the dissolution of the former, according to: 


$$
\mathrm{Ca}_{4} \mathrm{Al}_{2}(\mathrm{OH})_{12} \cdot\left(\mathrm{SO}_{4}\right) \cdot 6 \mathrm{H}_{2} \mathrm{O} \rightarrow 4 \mathrm{Ca}^{2+}+2 \mathrm{Al}(\mathrm{OH})_{4}^{-}+4(\mathrm{OH})^{-}+\mathrm{SO}_{4}{ }^{2-}+6 \mathrm{H}_{2} \mathrm{O} \text { [1] }
$$

Which leads to the precipitation of ettringite during the external sulfate attack:

$$
6 \mathrm{Ca}^{2+}+2 \mathrm{Al}(\mathrm{OH})_{4}^{-}+4(\mathrm{OH})^{-}+3 \mathrm{SO}_{4}^{2-}+26 \mathrm{H}_{2} \mathrm{O} \rightarrow \mathrm{Ca}_{6} \mathrm{Al}_{2}(\mathrm{OH})_{12}\left(\mathrm{SO}_{4}\right)_{3} \cdot 26 \mathrm{H}_{2} \mathrm{O} \text { [2] }
$$

Equation [2] indicates that a source of $\mathrm{Ca}^{2+}$ is also necessary for the growth of ettringite. In the cement paste calcium hydroxide $\mathrm{Ca}(\mathrm{OH})_{2}$ (portlandite) is the first phase to dissolve according to

$$
\mathrm{Ca}(\mathrm{OH})_{2} \rightarrow \mathrm{Ca}^{2+}+2 \mathrm{OH}^{-} \quad[3]
$$

Once the calcium hydroxide is no longer available, calcium silicate hydrates start to dissolve. Since calcium silicate hydrates are the continuous phase in the cement paste responsible for its strength and stiffness, the decalcification of these silicates lead to a deterioration of mechanical properties.

For the case of internal sulfate attack, the sources of sulfate ions are internal, for instance when aggregates contaminated with gypsum are used in the concrete manufacture. Delayed ettringite formation (DEF) is a special case of internal sulfate attack where concrete structures exposed to high temperature during curing can suffer expansion and cracking after a few years in operation. The typical manifestation of distress is the presence of voids around the coarse aggregate, indicating expansion of the cement paste. Often these voids are filled with ettringite crystals, which also fill other voids and cracks in the matrix. Although there is no consensus on the mechanism of expansion caused by DEF, there is a general agreement that ettringite is not a product of cement hydration when concrete is cured at temperatures exceeding $70 \mathrm{C}$. Instead, calcium monosulfoaluminate is formed with much of the sulfate adsorbed in the C-S-H. Later, during service, when sulfate ions are desorbed, the calcium monosulfoaluminate is transformed into ettringite, which, on exposure to high humidity, causes an expansion and microcracking in the matrix and generates a gap around the aggregate (Taylor, 1997). With time and in the presence of moisture, large crystals of ettringite develop from the smaller ones and fill the gap.

\section{Samples and texture analysis}

Samples were collected from a building in Recife, Brazil. The concrete foundations showed significant amount of distress. The reason for the expansive reaction was originally attributed to alkali-silica reaction (ASR), which involves certain siliceous aggregates and highly alkaline concrete pore solution reacting to produce an expansive alkali-silicate gel, which can imbibe water and then expand. Many dams, reinforced concrete bridges, and pavements require continuous repair or replacement because of cracks caused by this deleterious reaction. Field studies of damaged concrete structures documented that the distress can be caused both by ASR and DEF (Johansen et al. 1993, Pettifer and Nixon 1980, Shayan and Quick, 1992).

A sample of such deteriorating concrete shows conspicuous fractures filled with a fibrous material when viewed with a petrographic microscope (Fig. 1). The veins are about 10-20 $\mu \mathrm{m}$ wide and composed of calcium, aluminum and sulfur, as established by electron microprobe analyses.

We decided to use the microfocus beamline 12.3.2 at ALS for phase identification by diffraction and determination of preferred orientation. This beamline is mainly used to quantify residual lattice strains from single crystal Laue patterns (Tamura et al. 2003). A first series of experiments with white radiation, was unsuccessful because Laue patterns displayed extreme asterism. We then changed the strategy and used monochromatic radiation in transmission. We have previously done similar experiments with hard X-rays at APS (11-ID-C) and ESRF (ID15B) (e.g. Wenk et al. 2006, 2008). But at those beamlines the beam size is much larger than the 
dimensions of the ettringite vein. Microfocus beamline ID-11 at ESRF would also be suitable for similar experiments.

Sample preparation is delicate because standard petrographic thin sections cannot be applied to this material that is sensitive to heat, air and moisture. A flat surface was impregnated with Epoxy and then mounted with Superglue on a glass slide. With a diamond saw and kerosene as cooling agent a thin slice was prepared, then ground to $50 \mu \mathrm{m}$ and also sealed with epoxy. Finally the slice was removed from the glass slide and used for the investigation. Interesting areas were identified with a light microscope and marked (Fig. 1). Subsequently the sample was mounted on a translating goniometer on beamline 12.3.2 with a Mar 133 CCD detector more or less centered on the incident X-ray behind the sample. Images were collected between 30 and 60 sec. The wavelength was $1.5498 \AA(8 \mathrm{keV})$. The sample to detector distance was calibrated with a corundum (alumina) powder.

Diffraction images with a $2 \times 2 \mu \mathrm{m}$ beam immediately reveal a polycrystalline pattern with Debye rings that can be indexed as ettringite (Fig. 2). There are azimuthal intensity variations indicative of preferred orientation. Qualitatively the c-axis of this trigonal mineral can be associated with the fiber direction. The images were then further processed in Fit2D to correct for detector distance and detector orientation, and to extract integrated diffraction spectra over $10^{\circ}$ azimuthal intervals. These spectra were then used for a Rietveld refinement with the program MAUD (Lutterotti et al. 1997, 2004, version 2.073). The program refines in cycles background and instrumental parameters, crystallographic parameters and texture. As starting structure we used ettringite refined by Goetz-Neunhoeffer and Neunbauer (2006) (space group P 31c) that is similar to that of Hartman and Berliner (2006). The crystal structure was not refined as the range and resolution was not sufficient for a full Rietveld refinement and the structural intensities were reproduced sufficiently with the published structures. The texture was refined with two methods: With E-WIMV, assuming axial symmetry, and by refining a standard Gauss function with cylindrical symmetry. Both methods provide similar results. Figure $2 \mathrm{~b}$ is the average spectrum that illustrates a good fit with ettringite and Figure 3 compares a 2D plot of stacked observed spectra with recalculated spectra and documents a good fit for intensity variations with azimuth. The final $\mathrm{R}_{\mathrm{wp}}$ indices of the refinement were around $15 \%$ for both texture models and this is a good value considering a strong texture. The orientation distribution was then exported and used in Beartex (Wenk et al., 1997) to calculate pole figures and inverse pole figures.

\section{Results}

Pole figures view the sample perpendicular to the fracture surface. They display a strong maximum of c-axes perpendicular to the fracture surface (Fig. 4a) and correspondingly a-axes distributed in a girdle parallel to the fracture surface (Fig. 4b). The c-axis texture maximum is 28 multiples of a random distribution. This is a very strong alignment with a peak width at half maximum of less than $10^{\circ}$ for the E-WIMV analysis and $10.4^{\circ}$ for the standard function. Axially symmetric textures are conveniently represented in inverse pole figures (Fig. 4c). The plot confirms that the texture is basically produced by a c-axis alignment with no further constraints. We investigated several spots along the ettringite vein and found minor variations with local texture strengths varying between 15 and 30 m.r.d.

\section{Discussion and Conclusions}

A focused synchrotron X-ray beam proved to be an ideal method to investigate crystallite orientations in 10-20 $\mu \mathrm{m}$ thick veins of ettringite in concrete and the microfocus beamline at 
ALS emerged as a powerful tool to investigate preferred orientation of crystallites in very small volumes of poorly crystalline air- and heat-sensitive materials. By analyzing a thin slab, protected with epoxy coatings, in transmission areas as small as $2 \times 2 \mu \mathrm{m}$ could be selected for analysis with an X-ray energy as low as $8 \mathrm{keV}$. The 2D diffraction images could be processed with the Rietveld method, even though there is considerable spottiness (Fig. 2a) due to limited grain statistics.

In the case of this concrete sample the orientation of ettringite crystals is highly significant for the strength of the material. In ettringite the c-axis is the elastically stiffest direction (Speziale et al. 2008a), contrary to portlandite $\left(\mathrm{Ca}(\mathrm{OH})_{2}\right)$ that also shows preferred orientation in veins (Detwiler et al. 1988) and where the c-axis is elastically softest (Speziale et al. 2008b). The single crystal elastic tensor of trigonal ettringite $\left(\mathrm{C}_{11}=35.1 \mathrm{GPa}, \mathrm{C}_{12}=21.9\right.$, $\left.\mathrm{C}_{13}=20.0, \mathrm{C}_{14}=0.6, \mathrm{C}_{33}=55.0, \mathrm{C}_{44}=11.0\right)$ was averaged over the orientation distribution, using the geometric mean method (Matthies and Humbert, 1993) providing stiffness coefficients $\mathrm{C}_{11}=36.3 \mathrm{GPa}, \mathrm{C}_{12}=21.7, \mathrm{C}_{13}=20.5, \mathrm{C}_{14}=0.0, \mathrm{C}_{33}=49.7, \mathrm{C}_{44}=10.6$, assuming axial symmetry . Figure 5 compares the stiffness for an ettringite single crystal with that for the vein aggregate. The anisotropy $(\mathrm{An}=200(\max -\min ) /(\max +\min ) \%)$ is $44 \%$ for the single crystal and $31 \%$ for the ettringite aggregate.

\section{Acknowledgements}

We acknowledge access to beamline 12.3.2. at ALS of LBNL and discussions with Sergio Speziale (Potsdam) The project was supported by research grants from KAUST (Award No. KUS-11-004021 to PJMM and HRW) and NSF (EAR 0836402). The Advanced Light Source is supported by the Director, Office of Science, Office of Basic Energy Sciences, Materials Sciences Division, of the U.S. Department of Energy under Contract No. DE-AC02-05CH11231 at Lawrence Berkeley National Laboratory and University of California, Berkeley, California.

\section{References}

Backstrom, S.P., Riekel, C., Abel, S., Lehr, H. \& Wenk, H.-R. (1996). J. Appl. Cryst. 29, 118124.

Detwiler, R. J., Monteiro, P. J. M., Wenk, H.-R.\& Zhong, Z.(1988). Cement and Concrete Research, 18, 823-829.

Dingley, D. (2004). J. Microscopy 213, 214-224.

Goetz-Neunhoeffer, F. \& Neubauer, J. (2006). Powder Diffraction 21, 4-11.

Hartman, M.R. \& Berliner, R. (2006). Cement and Concrete Research 36, 364-370.

Heidelbach, F., Riekel, C. \& Wenk, H.-R. (1999). J. Appl. Cryst. 32, 841-849.

Johansen, V, Thaulow, N. \& Skalny, J. (1993). Adv. Cem. Res. 5, 23-29.

Lonardelli, I., Wenk, H.-R., Lutterotti, L. \& Goodwin, M. (2005). J. Synchr. Rad. 12, 354-360.

Lutterotti L., Matthies S., Wenk H. -R., Schultz A. S. \& Richardson J. W. (1997). J. Appl. Phys. 81, 594-600.

Lutterotti L., Chateigner D., Ferrari S. \& Ricote J. (2004). Thin Solid Film 450, 34-41.

Matthies, S. \& Humbert, M (1993). Physica Status Solidi, B177, K47-K50. 
Mehta, P.K. \& Monteiro, P.J.M. (2006). Concrete. Microstructure, Properties, and Materials. Third Ed. McGraw-Hill, New York, 659pp.

Pettifer, K. \& Nixon, P.J. (1980). Cement and Concrete Research 10, 173-181

Player, M.A., Marr, G.V., Gu, E., Savaloni, H., Oncan, N. \& Munro, I.H. (1992). J. Appl. Cryst. 25, 770-777.

Shayan, A. \& Quick, G.W. (1992). A.C.I. Mater. J. 89, 348-361.

Speziale, S., Jiang, F., Mao, Z., Monteiro, P. J.M., Wenk, H.-R., Duffy, T. S. \& Schilling, F. (2008a). Cement and Concrete Research 38, 885-889.

Speziale, S., Reichmann, H.J., Schilling, F.R., Wenk, H.R.\& Monteiro, P.J.M. (2008b). Cement and Concrete Research 38, 1148-1153.

Tamura, N., MacDowell, A.A., Spolenak, R., Valek, B.C., Bravman, J.C., Brown, W.L., Celestre, R.S., Padmore, H.A., Batterman, B.V. \& Patel, J.R. (2003). J. Synchrotron Rad., 10, $137-143$.

Taylor, H.F.W. (1997). Cement Chemistry, $2^{\text {nd }}$. Ed., T Telford, London, 459pp.

Wenk, H.-R., Matthies, S., Donovan, J. \& Chateigner, D. (1998). J. Appl. Cryst. 31, 262-269.

Wenk, H.-R., Voltolini, M., Kern, H., Popp, H. \& Mazurek, M. (2008). The Leading Edge 27, 742-748.

Wenk, H-R, Lonardelli, I, Rybacki, E, Dresen G, Barton, N, Franz, H \& Gonzalez, G (2006) Phys. Chem. Minerals 33, 667-676. 


\section{Figures Captions}

Fig. 1. Optical micrograph of a thin section of concrete with cement paste (dark) and a large feldspar aggregate fragment (transparent). At the interface is a vein of fibrous ettringite (arrow).

Fig. 2. (a) Diffraction image of polycrystalline ettringite. Intensity variations along Debye rings are indicative of preferred orientation. (b) Diffraction pattern obtained by azimuthal average. Crosses are experimental data and line is the Rietveld fit.

Fig. 32 2-D representation of a stack of 36 diffraction spectra as function of azimuth (vertical) and diffraction angle transformed to $\mathrm{Q}=2 \pi / \mathrm{d}$ (horizontal). Bottom are observations, top the Rietveld fit. The pattern displays a strong texture and an excellent fit.

Fig. 4 Pole figures $(a, b)$ and inverse pole figure of the fiber axis (c) illustrating preferred orientation of ettringite. Equal area projection. Logarithmic contours in multiples of a random distribution.

Fig. 5. Elastic stiffness for trigonal ettringite single crystal in crystal coordinates (a) and vein aggregate projected on the fracture surface (b). 


\section{Figures}

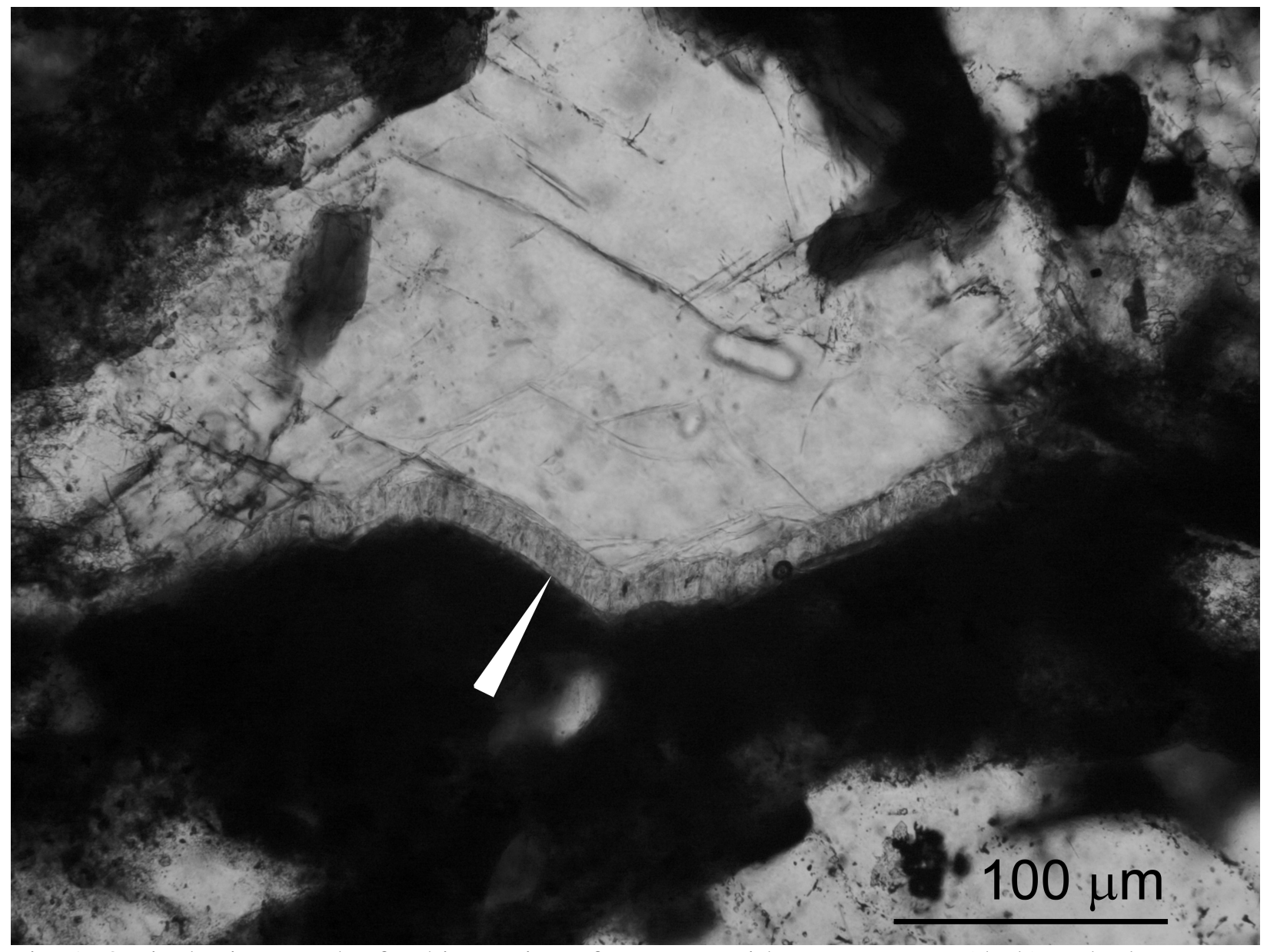

Fig. 1. Optical micrograph of a thin section of concrete with cement paste (dark) and a large feldspar aggregate fragment (transparent). At the interface is a vein of fibrous ettringite (arrow). 


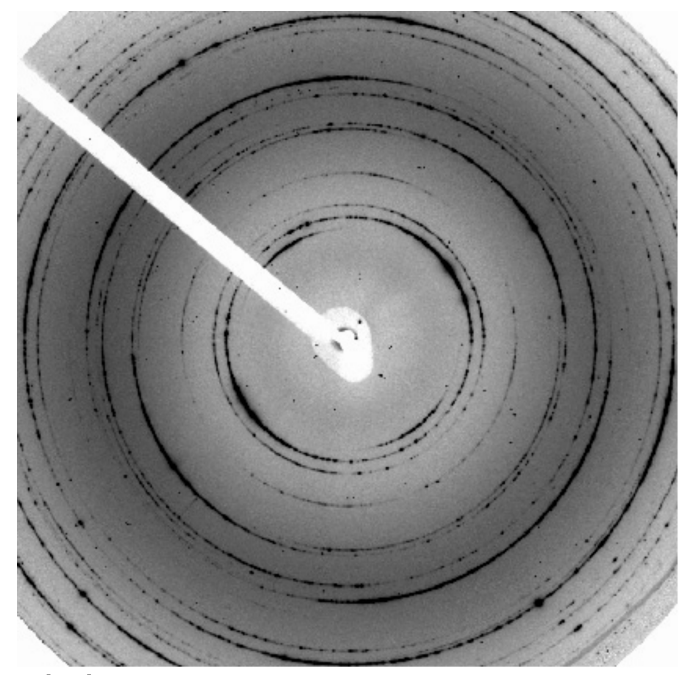

(a)

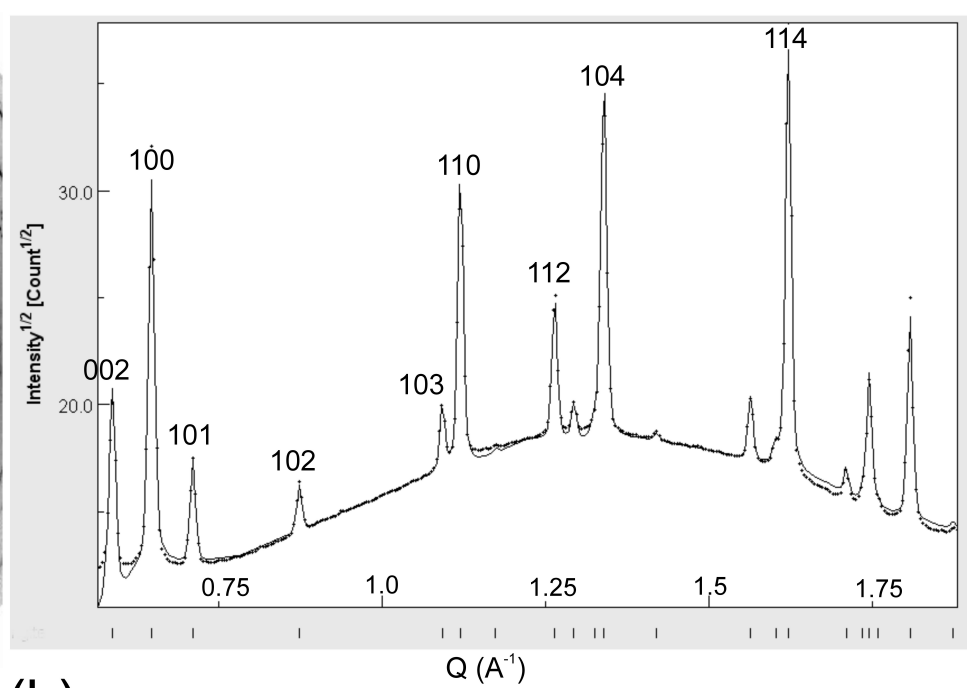

(b)

Fig. 2. (a) Diffraction image of polycrystalline ettringite. Intensity variations along Debye rings are indicative of preferred orientation. (b) Diffraction pattern obtained by azimuthal average. Crosses are experimental data and line is the Rietveld fit.

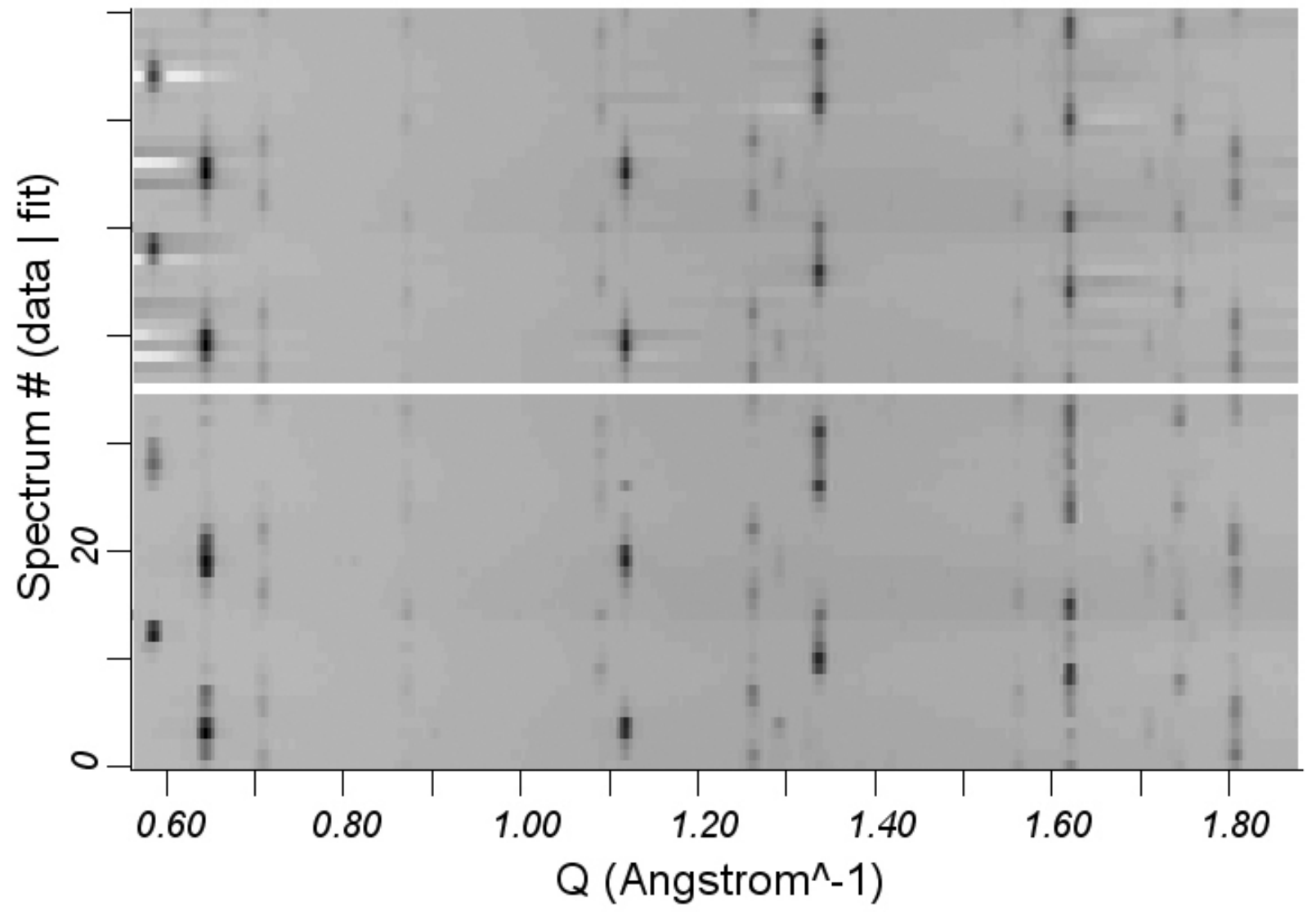

Fig. 3 2-D representation of a stack of 36 diffraction spectra as function of azimuth (vertical) and diffraction angle transformed to $\mathrm{Q}=2 \pi / \mathrm{d}$ (horizontal). Bottom are observations, top the Rietveld fit. The pattern displays a strong texture and an excellent fit. 


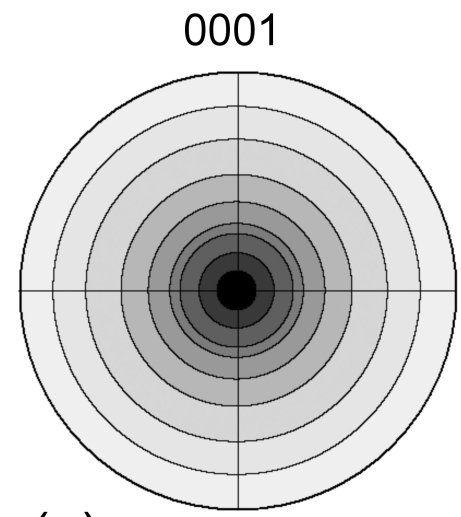

(a)

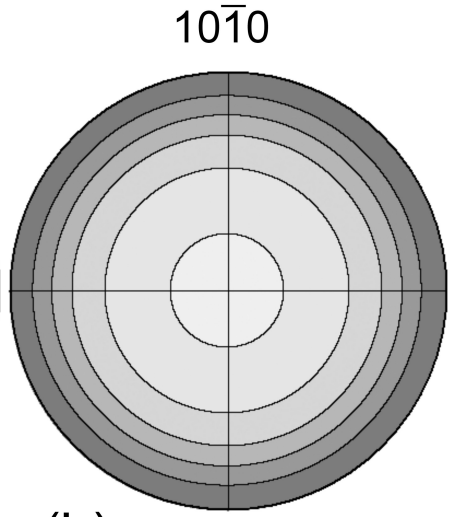

(b)

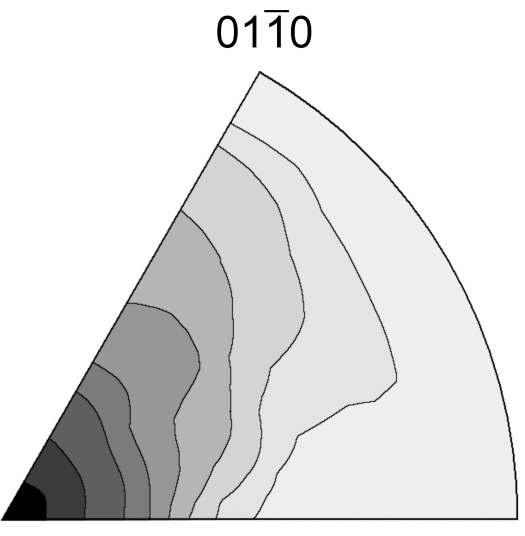

(c)

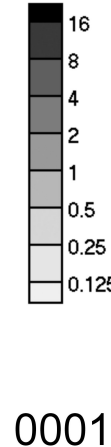

Fig. 4 Pole figures (a,b) and inverse pole figure of the fiber axis (c) illustrating preferred
orientation of ettringite. Equal area projection. Logarithmic contours in multiples of a random distribution.
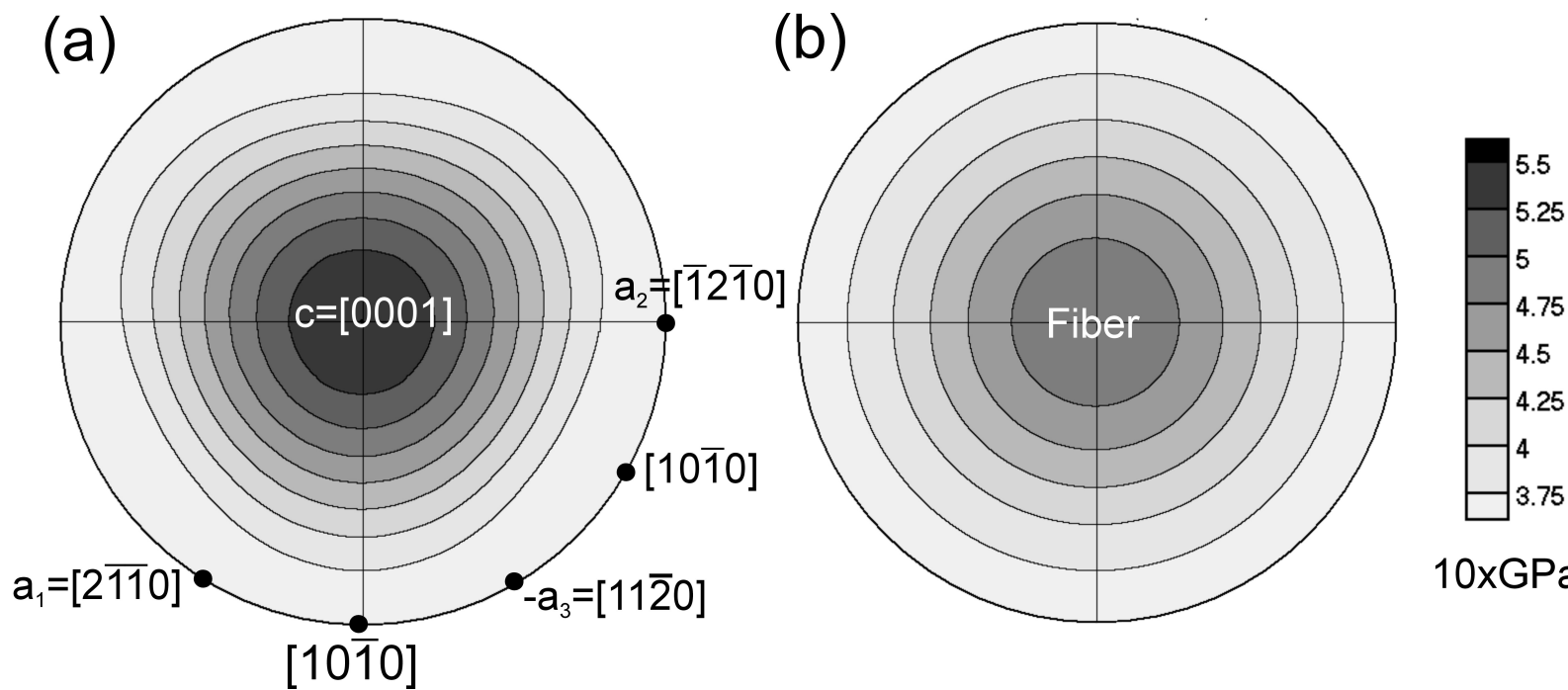

ig. 5. Elastic stiffness for trigonal ettringite single crystal in crystal coordinates (a) and vein aggregate projected on the fracture surface $(b)$. 